\title{
Induction of labour at the start of the new millennium
}

\author{
I Z MacKenzie \\ Reader in Obstetrics \& Gynaecology University of Oxford, John Radcliffe Hospital, Oxford, OX3 9DU \\ Correspondence should be addressed to I Z MacKenzie; Email: ray.anson@obs-gyn.ox.ac.uk
}

\begin{abstract}
Around $20 \%$ of all deliveries are preceded by labour induction, a proportion that has not varied dramatically over recent years. Fetal death was the only indication for labour induction centuries ago, while this is now a very rare indication, with prolonged pregnancy and maternal hypertensive disorders being the major indications for the last 50-60 years. Techniques for inducing labour have also changed from dietary delicacies and verbal threats giving way to physical stimulation mainly achieved by cervical stretching and amniotomy and more recently to sophisticated pharmacological manipulation using oxytocin and prostaglandins, based on our expanding knowledge of the physiological processes involved in spontaneous parturition. Relaxin, antiprogestins, nitric oxide as well as complementary medicines have also been explored in recent years. Successful induction is, however, still not guaranteed and there has been increasing emphasis during the past decade on exploring strategies for identifying the probability of success. Measurement of fetal fibronectin in cervical mucus, maternal serum nitrite/nitrate concentrations, ultrasound delineation of cervical form and electrical impedance measurements across the cervix are all being investigated. Safety, success, and patient satisfaction continue to be the major objectives with economic evaluations now becoming a significant factor in the search for the ideal induction method.

Reproduction (2006) 131 989-998
\end{abstract}

\section{Historical introduction}

The need to time delivery has been recognised and practised for centuries. Although the indications have clearly changed during the past 200 years from a need to expel a dead fetus to pre-emptive action to reduce the threat to fetal or maternal health, effective and safe methods of achieving delivery must always have been the primary objectives. Most methods of inducing labour before the last half century involved mechanical manipulations, including Galvinism, repeated pressurised douches, extra-amniotic aqua picea, tents, bougies and catheters. The issue of threats, incantations and chants was doubtless popular when nothing else was to hand, while the administration of potions and latterly castor oil, quinine and posterior pituitary extract were also utilised.

A number of folkloric or old wives' (old midwives') tales are still used today by women to encourage their labour to start. Among the more common approaches are frequent walking, vaginal intercourse, participating in heavy exercise, consumption of laxatives, spicy foods or herbal tea, nipple stimulation and administration of an enema (Schaffir 2002). Less well-known approaches include taking a hot bath, dancing, eating Chinese food, drinking warm gin or cranberry juice, and riding in a car over a bumpy road. During the past 40 years, labour induction has mostly involved combining the recognised advantages of physical manipulation with a pharmacological myometrial stimulant.

During the 1980s and 1990s patients' acceptance of when and how delivery was achieved became a significant and sometimes overpowering consideration; this has not necessarily always been in the long-term best interests of mother or fetus. In some countries the fear of legal redress if the pregnancy outcome is not entirely favourable has become so concerning that patient demands are frequently acquiesced to, and in many cases, requests for delivery by caesarean section are agreed although there is no clear medical indication. This article appraises the indications for labour induction and the frequency with which it is used, current frequently used methods and consideration of methods still under investigation, and thoughts on what the future might hold.

\section{Physiological background}

The cervix is essential in maintaining uterine stability during pregnancy. To achieve this, the maintenance of cervical shape and consistency is imperative since cervical 'ripening' is a physiological process occurring 
throughout the latter weeks of pregnancy and is completed with the onset of labour. When delivery is necessary and ripening has not had time to occur, or has failed to be initiated, this natural process has to be accelerated.

The cervix possesses a unique construction as described by Danforth (1947) to enable it to perform its various roles. It consists predominantly of a stromatous body of connective tissue that can be subdivided into a superficial loose zone and a deeper dense stromal zone. The main elements of this connective tissue are collagen together with a small amount of elastic tissue and an even smaller component of muscle fibres. The collagen is composed of dense regular fibrils arranged in parallel bundles held together by cross-links, with a few interspersed mast cells and other cellular elements. The ground substance is composed of proteoglycan complexes consisting of glycosaminoglycan side chains (GAGs) on core proteins linked to a hyaluronic acid chain that bind tightly. The dominant GAGs in the cervix are dermatan sulphate and chondroitin sulphate, both of which contain hyaluronic acid conferring additional binding strength and have hydrophilic properties. Fibroblasts with numerous long cytoplasmic processes radiating from one cell body to another, possibly similar to myometrial gap junctions, infiltrate the ground substance (UImsten 1986). With the advance of pregnancy, increased vascularity is seen and the fibroblasts become secretory, white cells and macrophages migrate out of vessel walls into the cervical stroma with an increase in water content. There is a reduction in collagen content and a relative increase in the glucuronic acid-containing GAG heparin sulphate that binds much less strongly (Uldbjerg et al. 1983; Ekman et al. 1986). Enzymatic breakdown of collagen fibrils by collagenases/matrix metalloproteinases produced by fibroblasts and polymorphonuclear leukocytes alongside leukocyte elastase, which catabolises elastin, leads to increased cervical compliance. The precise mediation and inter-relationships remain to be elucidated, but the prostaglandins and their synthase inhibitors are closely implicated with the known increase observed as pregnancy advances. Significantly there is reasonably strong evidence that the process of cervical ripening will occur without any detectable uterine contractions being stimulated (Ledger et al. 1985, Forman et al. 1992). Cytokines, notably IL-8 (Barclay et al. 1993), or platelet activating factor (PAF) (Sugano et al. 2001) and monocyte chemotactic protein1 (MCP-1) (Yamamoto et al. 2000) have been proposed as possible interactants in the remodelling process involved in cervical ripening, as has nitric oxide, synthesised by macrophages, myometrium and the cervix (Chwalisz \& Garfield 1998). As yet, the precise role, if any, for these agents in this physiological process remains to be elucidated (Fig. 1).

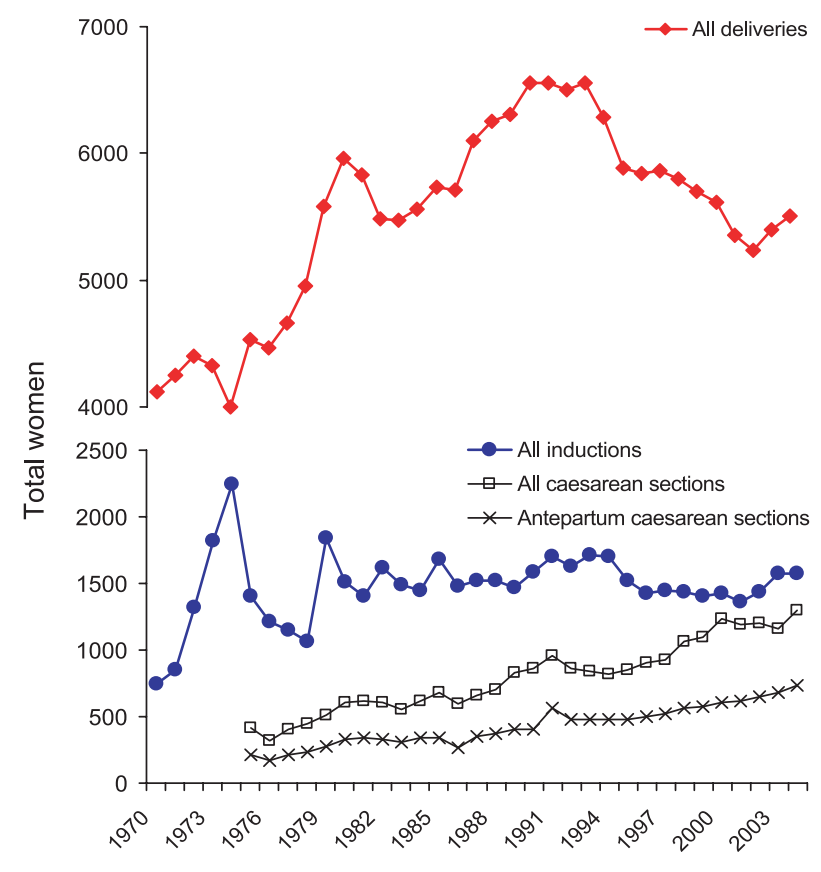

Figure 1 Annual labour induction and caesarean section numbers in Oxford since 1970.

Methods of inducing labour therefore are aimed at initiating and accelerating this physiological process.

\section{Major indications for labour induction}

The main indications for labour induction during the past 40 years can be subdivided into maternal, fetal, or social, or a combination of these, and they may either be evident or anticipated. Table 1 illustrates many of the indications that are widely acknowledged. An example of the relative frequency with which some of the major indications occur is shown in Table 2 of data derived from the obstetric department in Oxford for 14892 labour inductions during 1995-2004.

Specific definitions and the relative importance of the various indications for labour induction vary between obstetrician, obstetric unit and country. As an example, post-term, post-dates or prolonged pregnancy is probably the commonest indication in many units but definitions may include any gestation beyond 40,41 or 42 completed weeks' gestation. Some obstetricians consider that cervical state should determine the timing of delivery, particularly when "post-dates pregnancy" is the indication for induction. It must be remembered, however, that there is often a poor relationship between cervical favourability and gestational age (Anderson \& Turnbull 1969).

Hypertensive states constitute the second most common primary indication for labour induction in many obstetric units, again generally because of anticipated fetal or maternal problems rather than because of evidence of deteriorating maternal or fetal health. 
Table 1 Commonly quoted indications for inducing labour.

\begin{tabular}{lll}
\hline Fetal reasons & Maternal reasons & Non-medical reasons \\
\hline Clinically evident & & Specialist services availability \\
Growth restriction & Deteriorating health & - x-matched blood \\
Abruptio placentae & - renal & - anaesthesia \\
Polyhydramnios & - hypertension & - fetal surgery \\
Red-cell alloimmunisation & - psychological & Partner's availability \\
Diabetes mellitus & - malignancy & \\
Unstable fetal lie & - autoimmune diseases & Diabetic fragility \\
Fetal infection & Intra-uterine infection & Coagulopathy \\
Macrosomia & Antepartum haemorrhage & \\
& Polyhydramnios & \\
& Discomfort & \\
Statistically anticipated & Hypertension & \\
Prolonged pregnancy & Feto-pelvic disproportion & \\
Growth restriction & Short maternal height & \\
Previous obstetric history & Intra-uterine fetal death & \\
Ruptured membranes & Prior caesarean section \\
Breech presentation & Ruptured membranes \\
Diabetes mellitus & \\
Antepartum haemorrhage & \\
Multiple pregnancy & \\
Red-cell alloimmunisation & \\
\hline
\end{tabular}

The 'other' indications are varied, some probably universally accepted, such as recent or current antepartum haemorrhage, diabetes mellitus, red-cell alloimmunisation, demonstrable placental failure and previous unexplained stillbirth at term, and others with little logic, such as fetal breech presentation and suspected cephalo-pelvic disproportion; in many countries there is now a reluctance to encourage labour when there is a fetal breech presentation in a term pregnancy.

Labour induction performed for maternal request or convenience at term is generally frowned upon. However, the reluctance to accommodate such requests, believing it is not in the best interests of mother or fetus, is at variance with the willingness to allow patients to opt for delivery by elective caesarean section, usually performed before full term, particularly in cases such as fetal breech presentation or previous delivery by caesarean section. Such reluctance towards labour induction is not logical.

\section{Rates of labour induction}

It is difficult to compare rates between obstetric units, states or countries because of differences in definitions for induced and augmented labour. The following are examples of such discrepancies: (i) an oxytocic given following spontaneous membrane rupture without labour is variously called labour induction or augmentation; (ii) labour that follows prostaglandins given to ripen the cervix is variously called spontaneous or induced; (iii) attempts to ripen an unfavourable cervix that fail,

Table 2 Annual rates for indications for labour induction for 14892 women in Oxford 1995-2004.

\begin{tabular}{|c|c|c|c|c|c|c|c|c|c|c|c|}
\hline $\begin{array}{l}\text { Indication for } \\
\text { labour induction }\end{array}$ & 1995 & 1996 & 1997 & 1998 & 1999 & 2000 & 2001 & 2002 & 2003 & 2004 & Total \\
\hline $\begin{array}{l}\text { Post-dates and } \\
\text { membrane rupture } \\
\text { without labour }\end{array}$ & $51 \%$ & $48 \%$ & $51 \%$ & $46 \%$ & $44 \%$ & $47 \%$ & $49 \%$ & $47 \%$ & $48 \%$ & $46 \%$ & $47 \%$ \\
\hline Hypertensive states & $21 \%$ & $23 \%$ & $18 \%$ & $22 \%$ & $21 \%$ & $20 \%$ & $17 \%$ & $17 \%$ & $16 \%$ & $16 \%$ & $19 \%$ \\
\hline $\begin{array}{l}\text { Maternal distress } \\
\text { and convenience }\end{array}$ & $4 \%$ & $3 \%$ & $4 \%$ & $4 \%$ & $5 \%$ & $4 \%$ & $4 \%$ & $6 \%$ & $6 \%$ & $7 \%$ & $5 \%$ \\
\hline $\mathrm{APH}$ & $3 \%$ & $3 \%$ & $3 \%$ & $2 \%$ & $3 \%$ & $2 \%$ & $3 \%$ & $2 \%$ & $2 \%$ & $4 \%$ & $3 \%$ \\
\hline $\begin{array}{l}\text { Intra-uterine fetal } \\
\text { death }\end{array}$ & $1 \%$ & $2 \%$ & $1 \%$ & $1 \%$ & $2 \%$ & $1 \%$ & $1 \%$ & $2 \%$ & $1 \%$ & $1 \%$ & $1 \%$ \\
\hline Various indications & $20 \%$ & $21 \%$ & $22 \%$ & $25 \%$ & $25 \%$ & $26 \%$ & $26 \%$ & $26 \%$ & $26 \%$ & $26 \%$ & $24 \%$ \\
\hline Total inductions & 1518 & 1450 & 1469 & 1464 & 1434 & 1456 & 1394 & 1482 & 1601 & 1624 & 14892 \\
\hline $\begin{array}{l}\text { Hospital induction } \\
\text { rate }\end{array}$ & $26 \%$ & $25 \%$ & $25 \%$ & $25 \%$ & $25 \%$ & $26 \%$ & $26 \%$ & $28 \%$ & $30 \%$ & $30 \%$ & $27 \%$ \\
\hline $\begin{array}{l}\text { Hospital 'timed*' } \\
\text { delivery rate }\end{array}$ & $34 \%$ & $33 \%$ & $33 \%$ & $34 \%$ & $35 \%$ & $36 \%$ & $37 \%$ & $40 \%$ & $42 \%$ & $42 \%$ & $37 \%$ \\
\hline
\end{tabular}

\footnotetext{
*Includes all inductions and antepartum caesarean sections. APH; ante-partum haemorrhage.
} 
with delivery arranged by caesarean section, is variously called failed induction or elective caesarean section. All should logically be included in induction statistics, while a case can be made to consider labour inductions and antepartum caesarean sections under the general heading 'timed deliveries'.

The recent analysis by Kirby (2004) reviewing data on induction of labour in the United States from 1990 to 2002 found a marked discrepancy between the rates quoted by the National Centre for Health Statistics and the persistent $3 \%$ lower rates quoted by birth certification analyses. Most notable, however, was the increase in inductions from around $5-10 \%$ of deliveries in 1990 to around $17-21 \%$ by 2002 . During the early part of this period, the national rate for caesarean section in the United States was relatively static at around $21-22 \%$, followed by a sudden escalation to $26 \%$ in 2002 . This was thought to be related to a gathering momentum against encouraging labour in women previously delivered by caesarean section.

The induction of labour rate in England for 1985 (Department of Health 1988) was $17.5 \%$ and a survey of consultant obstetric units in the United Kingdom in 1989-90 reported the rate at 17\% (MacKenzie \& Boland 1992); rates for individual units varied between $4 \%$ and $37 \%$. Induction rates were not related to caesarean section rates in these units, as had been suggested was a consequence of high induction rates in the 1970s. The rate remained relatively constant between 1995 and 2004 at around $20 \%$ with an increase in planned caesarean section from $7 \%$ to $10 \%$ over the same period
(Government Statistical Services for the Department of Health 2005). The relevant statistics relating to labour induction and caesarean sections over the past 30 years in Oxford are illustrated in Figure 2. These show that after the dramatic increase in inductions experienced during the early part of the 1970 s, with a peak of $56 \%$ of deliveries followed induction, there was a dramatic fall and since the early 1980 s the induction rate has remained remarkably constant at around $25 \%$ of all maternities. There has, however, been a continuous increase in the proportion of deliveries managed by caesarean section, an increase that accelerated from the latter part of the 1990s with an overall increase in 'timed' deliveries to $40 \%$ and more by 2002 . The recent experience for total caesarean sections in the United States was not observed in the figures from this large obstetric unit in the United Kingdom.

\section{Current methods of inducing labour}

During the last 30 years the state of the uterine cervix has been recognised as having a major influence on the success of attempts to induce labour. It is common practice to describe methods of labour induction when the cervix is unripe or unfavourable and those used when the cervix is favourable. In reality, this is a continuum.

Two different approaches to labour induction are used, often in combination: one relies upon pharmacological agents to modify cervical form with or without stimulating uterine contractions, and the other uses mechanical stimulation to provoke cervical effacement,

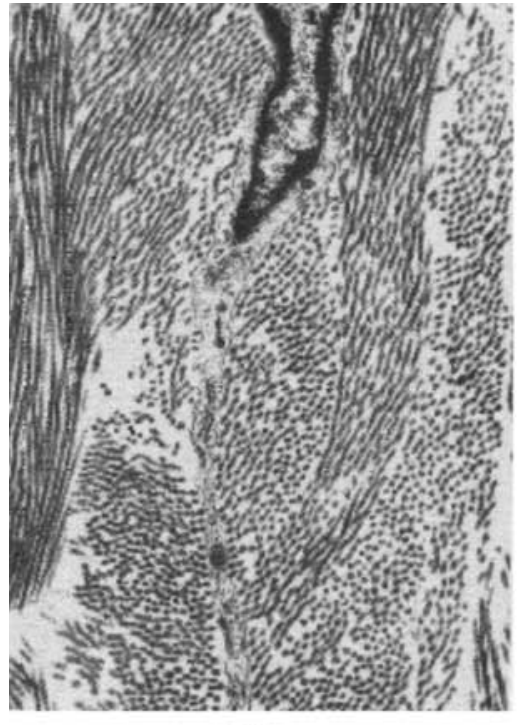

(a)

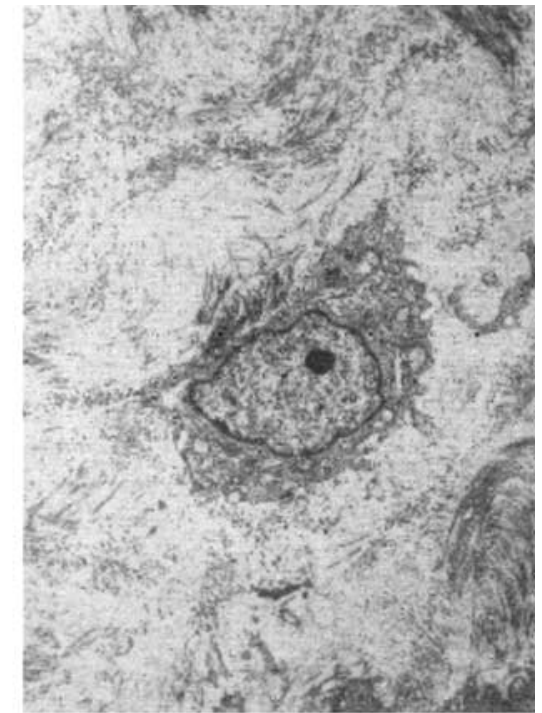

(b)

Figure 2 Electron micrographs of the ovine cervix illustrating the changes in morphology resulting in cervical ripening with the onset of parturition. (a) A 130 day pregnancy cervix with an inactive fibroblast with little cytoplasm and a filamentous process projecting between collagen fibril bundles ( $\times 10$ 400). (b) A parturient cervix showing complete disorganisation of fibril bundles and a typically active fibroblast $(\times 3400)$. (Parry \& Elwood 1981) Reproduced by kind permission of the publishers. 


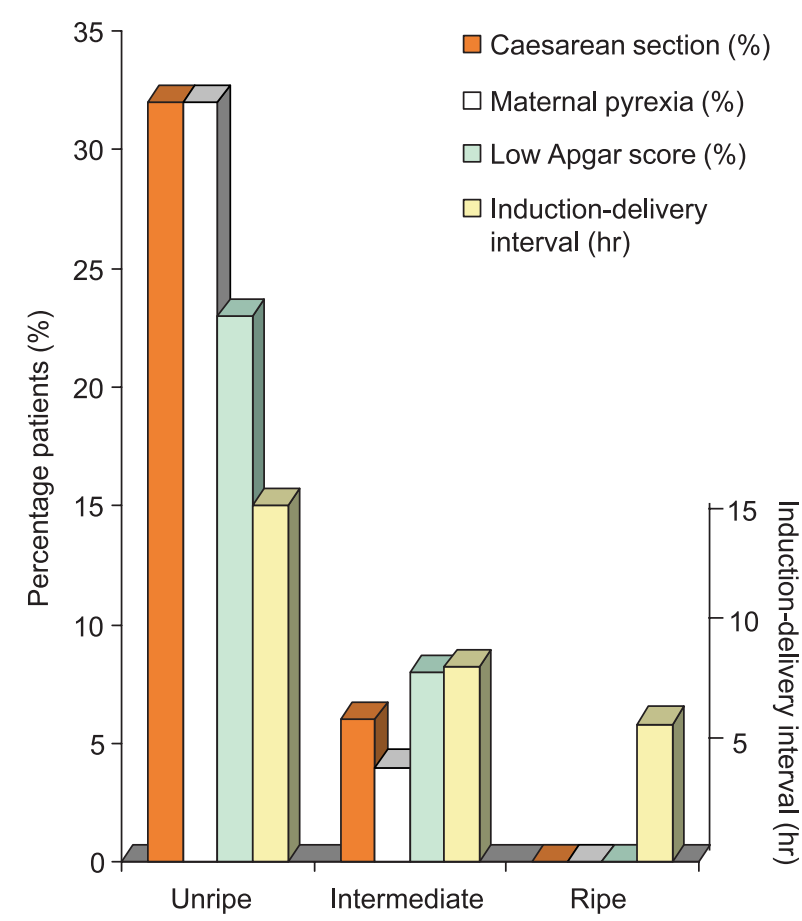

Figure 3 Influence of the condition of the cervix on the outcome of induced labour managed by low amniotomy and intravenous Syntocinon titration. (Data derived from (Calder et al. 1974)).

dilatation and ultimately uterine contractions. As a general principle, the simplest inductions are those performed when the cervix is ripe and probably precede the spontaneous onset of labour by a few hours to a day or two, and a mechanical technique alone is required. For the most difficult inductions, when the cervix is very unripe, a combination of a pharmacological agent, possibly involving more than one drug is followed by a mechanical stimulus.

\section{Prostaglandins}

By the mid-1980s the prostaglandins had become established as the most effective pharmacological agents for inducing labour when the cervix is unripe. A variety of administration routes had been explored during the preceding years including oral, intravenous, sublingual, rectal, intra-amniotic, extra-amniotic, intracervical, endocervical, and vaginal administration. The vaginal route was found to be the most acceptable, providing good efficacy and acceptability for the parturient and is now the preferred choice.

Currently only prostaglandin $\mathrm{E}_{2}\left(\mathrm{PGE}_{2}\right)$ is licensed for use for labour induction in cases of viable pregnancies. Commercially available vaginal preparations of $\mathrm{PGE}_{2}$ include a dry vaginal tablet, a viscous gel, and a nonbiodegradable hydrogel pessary. Treatment schedules vary from a single administration of the hydrogel pessary
$10 \mathrm{mg}$ or viscous gel $1 \mathrm{mg}$ or $2 \mathrm{mg}$ or repeated treatments at six-hourly intervals of the gel for a maximum of two doses or the dry tablet $3 \mathrm{mg}$ for a maximum of three doses.

The original randomised controlled studies comparing $\mathrm{PGE}_{2}$ and placebo for induction when the cervix was unfavourable showed dramatic reductions in the rates of failed inductions, prolonged labours, and delivery by caesarean section when prostaglandins were used. During the last 10 years, with a much more conservative approach to obstetric care and very high consumer expectations for labour outcome, resort to caesarean section is now much more ready and any attempts to try and demonstrate improved efficacy with new induction strategies require studies involving very large numbers to identify small significant improvements.

There remains a preparation of $\mathrm{PGE}_{2} 0.5 \mathrm{mg}$ in a small volume of viscous gel for endocervical administration in those women with an unfavourable cervix. The results obtained using this approach are generally little different from those obtained with vaginal administration and with the increased attention and added intervention required for placement of this gel in the cervical canal the method is rarely used in the United Kingdom.

During the past 15 years the introduction of misoprostol, the $\mathrm{PGE}_{1}$ analogue which, unlike $\mathrm{PGE}_{2}$, is stable at room temperature and is effective if taken orally, has been the major focus of attention for labour induction. It is also considerably cheaper than the alternative prostaglandin. Many of the studies reported have explored different doses and variable repeat dosing intervals and at present it would appear that misoprostol $25 \mu \mathrm{g}$ at $4-6 \mathrm{~h}$ intervals would be appropriate. Unfortunately there are very few studies that have examined outcomes in nulliparae and multiparae separately; studies involving women of mixed parity can potentially obscure important differences in clinical efficacy. The report by van Gemund et al. (2004) involving more than 600 patients did analyse parity groups separately but unfortunately the groups were somewhat heterogeneous and included women previously delivered by caesarean section; dramatic differences were not observed between repeated doses of misoprostol or $\mathrm{PGE}_{2}$ inductions. With a suggested possible increase in incidence of hyperstimulation with misoprostol noted in a number of series, it seems that it will be some time yet before this preparation can be recommended over the alternative licensed preparations available for clinical use. There is no preparation of the appropriate dose commercially available and local hospital pharmacies are required to manufacture the desired dose, contrary to current United Kingdom guidelines.

\section{Oxytocin}

Since du Vigneaud synthesised Syntocinon from the nona-peptide oxytocin in the 1950s (den Hertog et al. 
2001), it has been used by intravenous infusion for the majority of women having their labour induced. Although still used as the primary induction agent occasionally, it is more frequently given to assist the induction process using prostaglandins when the cervix is unfavourable or as an adjunct to low amniotomy in more favourable cases.

Protocols using intravenous infusions of oxytocin that are used these days are largely based on the work of Turnbull and Anderson (1968). Although originally given as a constant low dose infusion at less than $10 \mathrm{mU} / \mathrm{min}$, this has been replaced by titrated doses, determined by the intensity and frequency of uterine contractions assessed clinically by staff adjusting the infusion rate using mechanical pumps or electronic drip counters. Alternatively, automatic infusion pumps governed by intrauterine contraction pressures using solid-state pressure transducers have been used providing an automatic increase or decrease in rate with the theoretical avoidance of overdosage (Francis et al. 1970). These are usually set at a starting rate around 1-4 $\mathrm{mU} / \mathrm{min}$ and increase variably (Lamont et al. 1991), arithmetically (Kurup et al. 1991) or logarithmically (Toaff et al. 1978) at 15-30 min intervals often to a maximum of around $32 \mathrm{mU} / \mathrm{min}$, or until satisfactory labour has been established; occasionally higher rates may be required. There is evidence that continuous intravenous infusions of oxytocin to induce or augment labour downregulate myometrial oxytocin receptors (Phaneuf et al. 2000); the clinical consequence of this, however, is uncertain. While a pulsed administration of oxytocin has been tried to reduce the risk of overdosage (Pavlou et al. 1978, Salamalekis et al. 2000) this approach has not been widely adopted. Most consider that the rate required to establish labour should be maintained into the second stage, and increased once the third stage of labour is reached, being maintained for approximately an hour following delivery of the placenta and membranes.

The place of amniotomy for inductions combined with intravenous oxytocin continues to be debated. Most obstetricians combine the two with low amniotomy followed by intravenous oxytocin titration immediately or within an hour, while others advocate a delay of 4-6 h. Alternatively, a titrated infusion of oxytocin can be started and amniotomy delayed until contractility is established in cases where the presenting part is very mobile above the pelvic brim, reducing the chances of a malpresentation developing and serious consequences for mother and fetus; this approach is frowned upon by some.

\section{Membrane sweeping and amniotomy}

For those women keen to avoid as much intervention as possible, the practice of cervical stretching and membrane sweeping performed during a vaginal examination in the antenatal clinic has been shown to result in established labour in around $70 \%$ of cases if repeated daily over three days (Swann 1958).

Amniotomy, a procedure involving puncturing the membranes and releasing the amniotic fluid contained beneath the presenting fetal part in the maternal pelvis, is widely practised when the cervix is favourable. There is a widely held view that the manipulation of the cervix and vagina during the amniotomy provokes a release of oxytocin from the posterior pituitary via the Ferguson reflex and this is followed a few minutes later by a release of prostaglandins into the uterine vein, encouraging uterine contractility (Turnbull \& Anderson 1978). This procedure was the cornerstone of labour induction before effective pharmacological agents became available. It remains a part of most labour inductions and when the cervix is very favourable and the woman is most probably on the point of commencing spontaneous labour, low amniotomy is often all that is required. In less favourable cases, the amniotomy is usually followed after an hour or two with the addition of an infusion of Syntocinon, while in the unfavourable case an amniotomy is usually performed after previously administered prostaglandins have provoked cervical ripening to permit the surgical procedure.

\section{Recently explored methods}

\section{Antiprogestins}

Epostane, the $3 \beta$-hydroxy dehydrogenase inhibitor, and subsequently mifepristone, the progesterone receptor blocker, were shown to have a dramatic effect upon reducing induction to abortion intervals during second trimester therapeutic abortion (Selinger et al. 1987, Hill et al. 1990). It was hoped that a similar effect might be seen for labour induction at term but subsequent experience has not been encouraging. Cervical ripening can occur with labour induced following mifepristone administration but there was no reduction in caesarean sections with placebo in one of the first studies (Frydman et al. 1992). A more recent large study involving mifepristone $200 \mathrm{mg}$ produced very similar conclusions but unfortunately women of mixed parity were studied and conclusions must be guarded (Wing et al. 2000). With the limited experience to date there must be some uncertainty about the overall safety for the fetus and neonate with observed changes in fetal aldosterone concentrations (Hill et al. 1991). It remains a possibility that this drug could be used to improve the outcome of labour induction in the future.

\section{Oestrogens}

With the ever-increasing concentrations of oestrogen in the maternal circulation leading to term pregnancy, the belief that this could be a trigger for the onset of 
spontaneous labour led to studies exploring oestrogens for the induction of labour. Oestradiol gel given extraamniotically, endocervically or vaginally or oestradiol intramuscularly and oestriol gel extra-amniotically have been shown to produce some improved cervical favourability with minimal myometrial stimulation (Thiery et al. 1979, Magnani \& Cabrol 1986). When formal induction is performed $12-24 \mathrm{~h}$ later, there appears to be little improvement in the outcome of labour. However, since oestradiol has a tenfold higher oestrogenic potency than oestriol and there was a considerable dosage range in these studies, the true value of oestrogens for cervical ripening remains uncertain but present evidence suggests their role is probably very limited.

\section{Dehydroepiandrosterone sulphate}

Intravenous dehydroepiandrosterone sulphate (DHEAS), which is transformed into oestrogens in the fetoplacental unit, has been explored as a possible cervical ripening agent, achieving effacement without inducing uterine contractions. The results were not encouraging when DHEAS was injected intravenously twice a week from 38 weeks' gestation and compared with placebo (Sasaki et al. 1982) and the concept received little further attention.

\section{Relaxin}

This polypeptide has been studied in humans, using purified porcine relaxin 1-4 mg in viscous gel vaginally or endocervically. It was hoped that it would have the same properties as exhibited in certain animal species. To date, there have been no well-conducted trials to determine its value for ripening the unfavourable cervix and enhancing the outcome of induced labour without stimulating uterine activity, and more studies enabling a critical scientific assessment to be made would be necessary before considering it to be of any clinical value. With the production of recombinant human relaxin, interest was renewed. Trials to date exploring different dosages, given vaginally, indicate there is no evidence that doses of 1-4 mg cause any maternal or fetal toxicity (Bell et al. 1993), but unfortunately there also appears to be little evidence of any therapeutic effect (Brennand et al. 1995). Further studies with larger doses and alternative administration methods are required before large clinical trials should be mounted. Enthusiasm for this agent for labour induction must at present be muted.

\section{Nitric oxide}

There have been a number of studies suggesting that nitric oxide is involved in the process of cervical ripening during the latter stages of pregnancy (Thomson et al. 1997,
Chanrachakul et al. 2002). Nitric oxide donors can induce cervical ripening by stimulating the production of prostaglandins and thromboxane from the cervix (Ledingham et al. 1999) and the local application of glyceryl trinitrate and isosorbide mononitrate during the first and third trimesters of pregnancy has been studied examining the effect on cervical resistance (Chwalisz et al. 1997). Both agents reduce cervical resistance but at the expense of some side effects, most notably headache, nausea and vomiting, or dizziness. Importantly the improved cervical favourability can be achieved with little provoked uterine contractility. This has obvious potential benefits for the vulnerable pregnancy, but at present there is limited evidence of enhanced outcomes for mother or fetus. Further work is needed before conclusions can be finally drawn.

\section{Natural and complementary medicine methods}

Homoeopathy has been used in recent years for labour induction but a recent literature review identified only one prospective controlled trial examining the use of the herb 'caulophyllum' in a small group of women and concluded there was insufficient information from which to try to draw any conclusion at present (Smith 2001), although there have been concerns expressed about neonatal morbidity resulting from its use (Finkel \& Zarlengo 2004).

Breast stimulation has been suggested as an effective inexpensive non-medical means of inducing labour. A Cochrane Database review of six randomised controlled trials involving 719 women reported a significant reduction in the number of women with a favourable cervix not in labour $72 \mathrm{~h}$ following the start of nipple stimulation compared with no intervention. There was, however, no reduction in the need for delivery by caesarean section (Kavanagh et al. 2001b).

Acupuncture is being used with growing enthusiasm in various aspects of care during pregnancy and childbirth. At present, however, although it has been used for the induction of labour and appears safe without any recognised teratogenic effects, there is very limited information upon its clinical effectiveness for this purpose (Smith \& Crowther 2001).

Sexual intercourse during the latter weeks of pregnancy has been suggested as a logical strategy to encourage labour since semen is presumed to contain the highest prostaglandin concentration of any body fluid. However, any role that sexual intercourse may have in the initiation of labour is uncertain since it could be due to the physical stimulation of the lower uterine segment, or endogenous release of oxytocin as a result of orgasm or the Ferguson reflex or from the direct action of the prostaglandins in semen. A review of the relevant literature on this subject led the reviewers to conclude that it must be difficult to standardise sexual intercourse as an intervention to allow meaningful comparisons with 
other methods of induction of labour particularly for randomised studies involving a no-treatment or placebo group; trial violations could be difficult to identify (Kavanagh et al. 2001a). The one report cited involving 28 women did not allow any conclusion to be reached (Benvold et al. 1987).

\section{Predicting the success of labour induction}

Cervical condition exerts a significant influence upon induced labour outcome and in consequence the decision about how to induce labour must take account of the favourability of the cervix. To assist the obstetrician in deciding which way to induce labour a cervical scoring system is often used. More than 12 different pelvic or cervical scoring schemes have been described during the past 70 years, but the semi-quantitative clinical scoring system described by Bishop is the one most widely employed (Bishop 1964). Table 3 illustrates the components of Bishop's pelvic scoring system: a score of four or less is generally regarded as being unfavourable for labour induction. An objective cervical scoring system is also essential as a research tool to enable comparisons of different induction methods and protocols to be made and to facilitate new methods to be introduced and developed.

Fetal fibronectin (FFN) concentrations in cervical transudate represent a laboratory approach and have been shown to correlate with induced labour outcome with concentrations greater than $50 \mu \mathrm{g} / \mathrm{ml}$ associated with a favourable cervix and reduced intrapartum morbidity (Ekman et al. 1995). A review of eight reports concluded that a positive FFN was associated with significantly shorter delivery intervals than when a negative FFN result is obtained (Kiss et al. 2000). Since this assessment can be performed at the bedside, and there is evidence of circadian changes in uterine activity and responses to prostaglandins (Haluska et al. 1987, MacKenzie 1987), an assessment of FFN might assist in determining the most appropriate time during the working day when to initiate an induction.

Ultrasound assessment of the cervix has been investigated as a way of predicting the likely outcome of induced labour as an alternative to clinical digital examination. Studies have explored possible relationships between cervical length, internal cervical os shape and assessment of the angle between the cervical axis and the wall of the inferior segment of the uterus (Chandra et al. 2001, Pandis et al. 2001). The results from many published studies, some prospectively stringently controlled and others observational, suggest that, as with clinical observations, there is quite wide variation in the predictive value.

Electrical impedance measurements across the surface of the cervix using a $8 \mathrm{~mm}$ tetrapolar pencil probe have been used to investigate correlations with clinical
Table 3 Components assessed for Bishop's pelvic scoring system (Bishop 1964).

\begin{tabular}{lcccc}
\hline Score & $\mathbf{0}$ & $\mathbf{1}$ & $\mathbf{2}$ & $\mathbf{3}$ \\
\hline Station of presenting & -3 & -2 & $-1 / 0$ & +1 \\
part (cm) & & & & \\
Cervical dilatation $(\mathrm{cm})$ & closed & $1-2$ & $3-4$ & $5+$ \\
Cervical effacement $(\%)$ & $0-39$ & $40-59$ & $60-79$ & $80+$ \\
Cervical consistency & Firm & Medium & Soft & \\
Position of cervix in & Posterior & Mid & Anterior & \\
pelvis & & & & \\
\hline
\end{tabular}

examination to assess cervical favourability ( $\mathrm{O}^{\prime}$ Connell et al. 2003). A statistically significant association was found with the resistivity and the favourability of the cervix. It has yet to be discovered whether this interesting method of assessment translates into a worthwhile clinical predictor.

Serum nitrite/nitrate levels have also been assayed in nulliparae undergoing prostaglandin induction of labour and using multiple regression analyses significantly lower levels of each were found in women who delivered within $15 \mathrm{~h}$ of labour induction compared with those delivering over a longer period (Facchinetti et al. 1998). Further examination of this apparent relationship is worth further study.

\section{Current uncertainties and areas for improvement}

Labour induction is not without its risks for the mother and particularly for the fetus. Inadvertent delivery of a pre-term baby has largely been eliminated by the widespread use of ultrasound assessment of gestation. The problems of fluid and electrolyte imbalance that sometimes accompanied prolonged Syntocinon infusions given to establish labour in unfavourable cases are a feature of the past. Failed attempts at induction are more common now than 20 years ago probably because of the belief (often mistaken) that any attempt at inducing labour should not persist beyond a few hours. Uterine hyperstimulation remains an infrequent but serious complication and can occur using any oxytocic agent; the consequences of this, if unrecognised, can be very serious for the fetus. The search for an induction method that modulates the unfavourable to favourable cervix without stimulating uterine contractions and improves the ultimate outcome of labour almost eliminating risk to the fetus remains the Holy Grail.

With the ever-tightening restrictions imposed by ethics committees on clinical study, tightly controlled financial resources and the constant anxiety of litigation, enthusiasm to conduct research into new treatment modalities or medicines during pregnancy and the intrapartum period has been severely tempered.

There remains a need to assess any possible longterm consequences for babies born to mothers whose 
labour had been induced with pharmacological agents. To date, apart from a very few short-term studies related to $\mathrm{PGE}_{2}$ (Van Pelt et al. 1984, MacKenzie \& McKinley 1996), there is a dearth of such information in the literature.

What remains important, however, is the consumer view of the care provided. Studies on this issue that have been reported produced conflicting results (Cartwright 1977, Stewart 1977, Kennedy et al. 1982, Shetty et al. 2005). With the increasing demand by women for deliveries by caesarean section, it may become more attractive to deliver this way than to attempt an induction when the cervix is very unfavourable, if the modelling proposed for assessing the risk of caesarean section enter into clinical practice (Smith et al. 2004).

With financial pressures on funding for healthcare services being felt in many countries, the issue of costbenefit equations is now an important factor to be taken into account when discussing alternative options for care. Thus not only must the method of labour induction be safe and acceptable for the mother and fetus, it must also be economic since there is evidence that planned delivery by caesarean section might possibly be the least costly option available (Morrison \& MacKenzie 2003).

\section{Acknowledgements}

The author declares that there is no conflict of interest that would prejudice the impartiality of this scientific work.

\section{References}

Anderson AB \& Turnbull AC 1969 Relationship between length of gestation and cervical dilatation, uterine contractility, and other factors during pregnancy. American Journal of Obstetrics and Gynecology 105 1207-1214.

Barclay CG, Brennand JE, Kelly RW \& Calder AA 1993 Interleukin-8 production by the human cervix. American Journal of Obstetrics and Gynecology 169 625-632.

Bell RJ, Permezel M, MacLennan A, Hughes C, Healy D \& Brennecke S 1993 A randomized, double-blind, placebo-controlled trial of the safety of vaginal recombinant human relaxin for cervical ripening. Obstetrics and Gynecology 82 328-333.

Benvold E, Gottlieb C, Svanborg K, Bygdeman M \& Eneroth P 1987 Concentration of prostaglandins in seminal fluid of fertile men. International Journal of Andrology 10 463-469.

Bishop EH 1964 Pelvic scoring for elective induction. Obstetrics and Gynecology 24 266-268.

Brennand JE, Calder AA, Leitch CR, Greer I, Chou MM \& MacKenzie IZ 1995 Recombinant human relaxin as a cervical ripening agent. British Journal of Obstetrics and Gynaecology 104 775-780.

Calder AA, Embrey MP \& Hillier K 1974 Extraamniotic prostaglandin E2 for induction of labour at term. British Journal of Obstetrics and Gynaecology 81 39-46.

Cartwright A 1977 Mothers'experiences of induction. British Medical Journal 2 745-749.

Chandra S, Crane JM, Hutchens D \& Young DC 2001 Transvaginal ultrasound and digital examination in predicting successful labor induction. Obstetrics and Gynecology 98 2-6.
Chanrachakul B, Herabutya Y \& Punyavachira P 2002 Randomized trial of isosorbide mononitrate versus misoprostol for cervical ripening at term. International Journal of Gynaecology and Obstetrics 78 139-145.

Chwalisz K \& Garfield RE 1998 New molecular challenges in the induction of cervical ripening; nitric oxide as the final metabolic mediator of cervical ripening. Human Reproduction 13 245-248.

Chwalisz K, Shi Q, Garfield RE \& Beir HM 1997 Cervical ripening after a local application of nitric oxide. Human Reproduction 12 2093-2101.

Danforth DN 1947 The fibrous nature of the human cervix, and its relationship to the isthmic segment in gravid and non-gravid uteri. American Journal of Obstetrics and Gynecology 53 541-557.

den Hertog CE, de Groot AN \& van Dongen PW 2001 History and use of oxytocics. European Journal of Obstetrics Gynecology and Reproductive Biology 94 8-12.

Department of Health 1988 Hospital Inpatient Enquiry of England and Wales for 1985. MB4 number 28. London, HMSO.

Ekman G, Granstrom L, Malmstrom A, Sennstrom M \& Svensson J 1995 Cervical fetal fibronectin correlates to cervical ripening. Acta Obstetricia et Gynecologica Scandinavica 74 698-701.

Ekman G, Malmstrom A, Uldbjerg N \& Ulmsten U 1986 Cervical collagen: an important regulator of cervical function in term labour. Obstetrics and Gynecology 67 633-636.

Facchinetti F, Gandolfi A, Longo M \& Volpe A 1998 Serum nitrites predict the response to prostaglandin-induced delivery at term. Journal of the Society of Gynecological Investigation 5 140-143.

Finkel RS \& Zarlengo KM 2004 Blue cohosh and perinatal stroke. New England Journal of Medicine 351 302-303.

Forman A, Ulmsten U, Banyai J, Wingerup L \& Uldbjerg N 1992 Evidence for a local effect of the intracervical prostaglandin E2 gel. American Journal of Obstetrics and Gynecology 143 756-760.

Francis JG, Turnbull AC \& Thomas FF 1970 Automatic oxytocin infusion equipment for induction of labour. Journal of Obstetrics and Gynaecology of the British Commonwealth 77 594-602.

Frydman R, Lelaidier C, Baton Saint Mleux C, Fernandez H, Vial M \& Bourget $\mathbf{P} 1992$ Labor induction in women at term with mifepristone (RU 486): a double-blind, randomized, placebo-controlled study. Obstetrics and Gynecology 80 972-975.

Government Statistical Services for the Department of Health 2005 NHS Maternity Statistics, England: 2003-2004. Bulletin 2005/10, 1-45. London, Crown Copyright.

Haluska GJ, Stanczyk FZ, Cook MJ \& Novy MJ 1987 Temporal changes in uterine activity and prostaglandin response to RU486 in rhesus macaques in late pregnancy. American Journal of Obstetrics and Gynecology 157 1487-1495.

Hill NCW, Selinger M, Ferguson J, Lopez-Bernal A \& MacKenzie IZ 1990 The physiological and clinical effects of progesterone inhibition with RU38486 (mifepristone) in the second trimester. British Journal of Obstetrics and Gynaecology 97 487-492.

Hill NC, Selinger M, Ferguson J \& MacKenzie IZ 1991 Transplacental passage of mifepristone and its influence on maternal and fetal steroid concentrations in the second trimester of pregnancy. Human Reproduction 6 458-462.

Kavanagh J, Kelly AJ \& Thomas J 2001 a Sexual intercourse for cervical ripening and induction of labour. Cochrane Database of Systematic Reviews CD003093.

Kavanagh J, Kelly AJ \& Thomas J $2001 b$ Breast stimulation for cervical ripening and induction of labour. Cochrane Database of Systematic Reviews CD003392.

Kennedy JH, Stewart P, Barlow DH, Hillan E \& Calder AA 1982 Induction of labour: a comparison of a single prostaglandin E2 vaginal tablet with amniotomy and intravenous oxytocin. British Journal of Obstetrics and Gynaecology 89 704-707.

Kirby RS 2004 Trends in labor induction in the United States: is it true that what goes up must come down?. Birth 31 148-151.

Kiss H, Ahner R, Hohlagschwandtner M, Leitich H \& Husslein P 2000 Fetal fibronectin as a predictor of term labor: a literature review. Acta Obstetricia et Gynecologica Scandinavica 79 3-7. 
Kurup A, Chua S, Arulkumaran S, Tham KF, Tay D \& Ratnam SS 1991 Induction of labour in nulliparas with poor cervical score: oxytocin or prostaglandin vaginal pessaries? Australian and New Zealand Journal of Obstetrics and Gynaecology 31 223-226.

Lamont RF, Neave S, Baker AC \& Steer PJ 1991 Intrauterine pressures in labours induced by amniotomy and oxytocin or vaginal prostaglandin gel compared with spontaneous labour. British Journal of Obstetrics and Gynaecology 98 441-447.

Ledger WL, Webster M, Harrison LP, Anderson ABM \& Turnbull AC 1985 Increase in cervical extensibility during labour induced after isolation of the cervix from the uterus in pregnant ewes. American Journal of Obstetrics and Gynecology 151 397-402.

Ledingham MA, Denison FC, Kelly RW, Young A \& Norman JE 1999 Nitric oxide donors stimulate prostaglandin $\mathrm{F}$ (2alpha) and inhibit thromboxane $\mathrm{B}(2)$ production in the human cervix during the first trimester of pregnancy. Molecular Human Reproduction $\mathbf{5}$ 973-982.

MacKenzie IZ 1987 The clinical use of prostaglandins for cervical ripening and induction of labour. In Eicosanoids and Reproduction, pp 195-224. Ed K Hillier. Lancaster: MTP Press.

MacKenzie IZ \& Boland J 1992 Current therapeutic uses of prostaglandins in obstetrics in the United Kingdom. Contemporary Reviews in Obstetrics and Gynaecology 5 9-14.

MacKenzie IZ \& McKinley E 1996 Paediatric follow-up study: follow up of infants delivered by spontaneous vaginal delivery, following PGE2 or oxytocin induction, or by caesarean section. In Propess-RS: A Clinical Review, pp 37-39. Eds AA Calder, MJNC Keirse \& IZ MacKenzie. Haslemere: Euromed Communications.

Magnani M \& Cabrol D 1986 Declenchement artificel du travail par la prostaglandine E2 apres maturation du col par l'estradiol. Inserm 151 109-118.

Morrison J \& MacKenzie IZ 2003 Caesarean Section on Demand. In Seminars in Perinatology, pp 20-33. Eds ME D'Alton \& I Gross. Philadelphia: W B Saunders.

O'Connell MP, Avis NJ, Brown BH, Killick SR \& Lindow SW 2003 Electrical impedance measurements: an objective measure of prelabor cervical change. Journal of Maternal Fetal and Neonatal Medicine 14 389-391.

Pandis GK, Papageorghiou AT, Ramanathan VG, Thompson MO \& Nicolaides KH 2001 Preinduction sonographic measurement of cervical length in the prediction of successful induction of labor. Ultrasound Obstetrics and Gynecology 18 623-628.

Parry D \& Elwood DA 1981 Ultrastructural aspects of cervical softening in the sheep. In The Cervix in Pregnancy and Labour, pp 74-84. Eds DA Elwood \& ABM Anderson. Edinburgh: Churchill Livingstone.

Pavlou C, Barker GH, Roberts A \& Chamberlain GVP 1978 Pulsed oxytocin infusion in the induction of labour. British Journal of Obstetrics and Gynaecology 85 96-100.

Phaneuf S, Rodriguez LB, TambyRaja RL, MacKenzie IZ \& Lopez BA 2000 Loss of myometrial oxytocin receptors during oxytocininduced and oxytocin-augmented labour. Journal of Reproduction and Fertility 120 91-97.

Salamalekis E, Vitoratos N, Kassanos D, Loghis C, Panayotopoulos N \& Sykiotis C 2000 A randomized trial of pulsatile vs continuous oxytocin infusion for labor induction. Clinical and Experimental Obstetrics and Gynecology 27 21-23.

Sasaki K, Nakano R, Kadoya Y, Iwao M, Shima K \& Sowa M 1982 Cervical ripening with dehydroepiandrosterone sulphate. British Journal of Obstetrics and Gynaecology 89 195-198.

Schaffir J 2002 Survey of folk beliefs about induction of labor. Birth 29 47-51.

Selinger M, MacKenzie IZ, Gillmer MDG, Phipps SL \& Ferguson J 1987 Progesterone inhibition in midtrimester termination of pregnancy: physiological and clinical effects. British Journal of Obstetrics and Gynaecology 94 1218-1222.
Shetty A, Burt R, Rice P \& Templeton A 2005 Women's perceptions, expectations and satisfaction with induced labour-a questionnairebased study. European Journal of Obstetrics Gynecology and Reproductive Biology 123 56-61.

Smith CA 2001 Homoeopathy for induction of labour. Cochrane Database of Systematic Reviews CD003399.

Smith CA \& Crowther CA 2001 Acupuncture for induction of labour. Cochrane Database of Systematic Reviews CD002962.

Smith GC, Dellens M, White IR \& Pell JP 2004 Combined logistic and Bayesian modeling of cesarean section risk. American Journal of Obstetrics and Gynecology 191 2029-2034.

Stewart P 1977 Patients' attitudes to induction and labour. British Medical Journal 2 749-752.

Sugano T, Narahara H, Nasu K, Arima K, Fujisawa K \& Miyakawa I 2001 Effects of platelet-activating factor on cytokine production by human uterine cervical fibroblasts. Molecular Human Reproduction $7475-481$.

Swann RO 1958 Induction of labour by stripping membranes. Obstetrics and Gynecology 11 74-78.

Thiery M, De Grezelle H, Van Ketz H, Voorhoof L, Verheugen C, Smis B, Gervis J, Derom R \& Martens G 1979 The effect of locally administered estrogen on the human cervix. Zeitschrift fur Geburtshilfe und Perinatologie 183 445-448.

Thomson AJ, Lunan CB, Cameron AD, Cameron IT, Greer IA \& Norman JE 1997 Nitric oxide donors induce ripening of the human uterine cervix: a randomised controlled trial. British Journal of Obstetrics and Gynaecology 104 1054-1057.

Toaff ME, Hezroni J \& Toaff R 1978 Induction of labour by pharmacological and physiological doses of intravenous oxytocin. British Journal of Obstetrics and Gynaecology 85 101-108.

Turnbull AC \& Anderson AB 1968 Induction of labour. 3. Results with amniotomy and oxytocin "titration". Journal of Obstetrics and Gynaecology of the British Commonwealth 75 32-41.

Turnbull AC \& Anderson ABM 1978 Uterine function in human pregnancy and labour. In Scientific Basis of Obstetrics and Gynaecology, pp 79-108. Ed RR Macdonald. Edinburgh: Churchill Livingstone.

Uldbjerg N, Ekman G \& Malmstrom A 1983 Ripening of the human uterine cervix related to changes in collagen glycosaminoglycans and, collagenolytic activity. American Journal of Obstetrics and Gynecology 147 662-666.

Ulmsten U 1986 The cervix. In Prostaglandins and their Inhibitors in Clinical Obstetrics and Gynaecology, pp 29-57. Eds N Bygdeman, M Berger \& LG Keith. Lancaster: MTP Press.

van Gemund N, Scherjon S, LeCessie S, van Leeuwen JH, van Roosmalen J \& Kanhai HH 2004 A randomised trial comparing low dose vaginal misoprostol and dinoprostone for labour induction. British Journal of Obstetrics and Gynaecology 111 42-49.

Van Pelt C, De Coster W \& Thiery M 1984 Preinduction cervical ripening with prostagladin E2: influence on psychomotor evolution in the first year. European Journal of Obstetrics Gynecology and Reproductive Biology 18 299-301.

Wing DA, Fassett MJ \& Mishell DR 2000 Mifepristone for preinduction cervical ripening beyond 41 weeks' gestation: a randomized controlled trial. Obstetrics and Gynecology 96 543-548.

Yamamoto T, Eckes B, Mauch C, Hartmann K \& Kreig T 2000 Monocyte chemoattractant protein-1 enhances gene expression and synthesis of matrix metalloproteinase- 1 in human fibroblasts by an autocrine IL-1a loop. Journal of Immunology 164 6174-6179.

Received 6 December 2005

First decision 19 January 2006

Revised manuscript received 14 February 2006

Accepted 16 February 2006 